\title{
Rapid method for direct identification of positive blood cultures by MALDI-TOF MS
}

\author{
YUELING WANG ${ }^{1}$, YAN JIN ${ }^{1}$, YUANYUAN BAI ${ }^{1}$, ZHEN SONG $^{1}$, WENJUN CHU ${ }^{1}$, \\ MENGQI ZHAO ${ }^{1}$, YINGYING HAO ${ }^{1,2}$ and ZHIMING LU ${ }^{1,2}$ \\ ${ }^{1}$ Department of Clinical Laboratory, Shandong Provincial Hospital Affiliated to Shandong First Medical University; \\ ${ }^{2}$ Department of Clinical Laboratory, Shandong Provincial Hospital, Cheeloo College of Medicine, \\ Shandong University, Jinan, Shandong 250021, P.R. China
}

Received February 18, 2020; Accepted August 27, 2020

DOI: $10.3892 /$ etm.2020.9365

\begin{abstract}
Application of matrix-assisted laser desorption ionization-time of flight mass spectrometry (MALDI-TOF MS) using positive blood cultures (BCs) is a revolution in identification of microorganisms in clinical microbiology laboratories. Although there are several commercial pretreatment protocols they are expensive. Here, we evaluated the performance of a locally produced Bioyong pre-treatment kit for the direct identification of microorganisms in positive BCs by MALDI-TOF MS method. The mocked positive BCs were performed using 200 Thermo aerobic blood culture bottles and 200 aerobic Scenker blood culture bottles. A total of 200 organisms were invovled, including 91 strains of Gram-positive bacteria, 97 strains of Gram-negative bacteria and 12 strains of Candida. The positive BCs were subcultured and identified by classical biochemical Vitek II testing as the gold standard of identification. The Bioyong pre-treatment kit could successfully identify microorganisms in $189(94.5 \%)$ Thermo positive BCs and 189 (94.5\%) Scenker positive blood cultures, respectively. In total, 94 (96.9\%) Gram-negative bacteria, 86 (94.5\%) Gram-positive bacteria and 9 (75.0\%) candida isolated from Thermo positive BCs were correctly identified to species level and 95 (97.9\%) Gram-negative bacteria, $86(94.5 \%)$ Gram-positive bacteria and $8(66.7 \%)$ candida isolated from Scenker positive BCs were correctly identified to species level. This method provides a rapid, accurate identification of bacteria and Candida within one hour in positive blood cultures. Routine application of this technique will improve the antimicrobial treatment within $24 \mathrm{~h}$ among the patients with bacteremia and candidemia.
\end{abstract}

Correspondence to: Dr Zhiming Lu or Dr Yingying Hao, Department of Clinical Laboratory, Shandong Provincial Hospital Affiliated to Shandong First Medical University, 324 Jing-Wu, Jinan, Shandong 250021, P.R. China

E-mail: r8s272@163.com

E-mail: luzhiming@sdu.edu.cn; haoyyjia@163.com

Key words: MALDI-TOF MS, blood culture, bacteremia, candidemia, Vitek II, Bioyong ${ }^{\circledR}$ kit

\section{Introduction}

Blood stream infections (BSIs) remain one of the most serious infections with high morbidity and mortality. Rapid identification of the causative microorganism and the correct initial anti-infection treatment is especially critical for sepsis patients. The delay of appropriate anti-infection treatment may increase the mortality of patients (1). Moreover, appropriate anti-infection therapeutic option determines the survival rate of patients (2). Accurate and rapid diagnosis of etiological diagnosis is the key to reduce the time and cost of hospitalization (3). Blood culture is still the most important diagnostic method for BSIs.

For positive blood cultures, the traditional laboratory process is performed based on Gram staining, subculture, biochemical identification and antimicrobial susceptibility tests. The laboratory reports commonly need 48-72 h. If the pathogen grows harsh or inert, the cycle will be even longer. In recent years, a variety of new rapid identification methods such as real-time quantitative PCR, multiple PCR, fluorescence in situ hybridization (FISH) and peptide nucleic acid hybridization (PNAFISH) have been introduced into the field of microbial identification (4). However, these methods are limited to detecting the target microorganisms. In addition, the cost of reagents and instruments of these methods is high.

In 2009, MALDI-TOF MS was firstly introduced into the field of clinical microbiology identification directly from positive blood cultures (BCs) (5). At present, MALDI-TOF MS is becoming more mature for pure colony identification with high accuracy and repeatability. In almost all studies, the identification accuracy of this method was better than the routinely used biochemical identification method, with the test cycle shortened and the required cost reduced (6).

There are several in-house methods for the identification of pathogens directly from BCs or other primary specimens developed. However, none is commonly used because there is no standardization. There are also several imported commercial kits in China, but the prices are relative high for routine operation in clinical laboratories. Bioyong kit is a recently developed pretreatment method to improve the performance of direct MALDI-TOF MS identification from positive BCs. The Bioyong sample preparation kit was produced in China locally, aimed to cut down costs and increase sensitivity. The 
aim of the present study was to analyse the performance of this method in flow of positive culture in clinical microbiology laboratory. To eliminate differences caused by the diversity of blood volume and blood component, mock-inoculated BCs were conducted. Moreover, to eliminate interference of different BCs bottles, Thermo and Scanker blood culture bottles were used in parallel.

\section{Materials and methods}

Collection of isolates. A total of 200 test strains (36 genera and 61 species) collected at Shandong Provincial Hospital Affiliated to Shandong First Medical University (Jinan, China) during August 2017 to February 2018 were recovered from the $-80^{\circ} \mathrm{C}$ refrigerator. In total, 91 strains of Gram-positive bacteria, 97 strains of Gram-negative bacteria and 12 strains of the fungi were adopted. Escherichia coli ATCC 8739 was recovered as a calibration.

The strains were inoculated on Columbia blood agar plate, except Haemophilus influenzae which was inoculated on chocolate agar medium. The strains of candida were inoculated on the Sabouraud Dextrose Agar (SDA). The bacteria strains were incubated at $35^{\circ} \mathrm{C}$ for $24 \mathrm{~h}$ and Candida were incubated for $48 \mathrm{~h}$. Single colony was picked and subcultured for mock-inoculated blood culture.

Mock-inoculated blood culture. A total of $2000 \mathrm{ml}$ blood was collected from 10 healthy volunteers for the stimulation of blood culture. Signed informed consent was obtained from the volunteers that participated in the study. The methods in this study were approved by the Ethics Committee of Shandong Provincial Hospital Affiliated to Shandong First Medical University and were carried out in accordance with the approved guidelines.

Bacterial/candidas suspension $(0.5 \mathrm{McF})$ was prepared using the turbidimetric (VITEK ${ }^{\circledR}$ Compact, bioMérieux, France) and diluted 100 times to $10^{6} \mathrm{cfu} / \mathrm{ml}$ (with $100 \mu \mathrm{l}$ to $10 \mathrm{ml}$ aseptic saline) and $50 \mu \mathrm{l}$ of $10^{6}$ dilution was added to $5 \mathrm{ml}$ blood with the final concentration of $10^{4} \mathrm{cfu} / \mathrm{ml}$. The blood was mixed with bacterial/candidas suspension was injected into blood culture bottle using aseptic syringe after the bottle mouth was sterilized with $75 \%$ alcohol. The blood culture bottles were mixed up and down several times and loaded on the automatic blood culture system. Two different kinds of aerobic blood culture bottles, including VersaTREK ${ }^{\mathrm{TM}}$ REDOX $^{\text {тм }} 2$ blood culture bottles (Thermo Fisher Scientific, USA) and Scenker blood culture bottles (Scenker, China), were used for the parallel test.

A total of $50 \mu \mathrm{l}$ aseptic saline was added to $5 \mathrm{ml}$ blood and injected into one set of blood culture bottles used as negative control. The negative control bottles were cultured on the automatic blood culture system for 5 days to eliminate any contamination during the procedure. The bottles injected with bacterial/candidas suspension without positivity within 5 days were excluded.

Identification by the routine method. The positive bottle was analyzed by Gram staining after signaled as positive by the automatic blood culture system. The positive cultures were simultaneously transferred onto chocolate plate and Columbia agar plate (Thermo Fisher Scientific, Inc.), and the pure colony was obtained for routine biochemical identification. The conventional biochemical identification was conducted with VITEK $2^{\circledR}$ Compact automatic biochemical identification system (VITEK $2^{\circledR}$ Compact, BioMérieux).

Sample pre-treatment for MALDI-TOF MS identification. The positive BCs were processed according the standard experimental procedure of Bioyong positive BC identification kits (Bioyong Technologies Inc.). A total of $200 \mu \mathrm{l}$ of the sample was drawn from the positive blood culture bottle to $1.5 \mathrm{ml}$ Eppendorf centrifuge tube; $40 \mu \mathrm{l}$ of Reagent I of positive BCs identification kits for blood culture was added to the sample centrifuge tube and shocked for $5 \mathrm{sec}$, and the mixture was placed for $8 \mathrm{~min}$ at room temperature. Then $1,000 \mu \mathrm{l}$ of Reagent II of positive BC identification kits was added to the tube and vortexed for $5 \mathrm{sec}$. The mixture was centrifuged for $3 \mathrm{~min}$ at $300 \mathrm{x} \mathrm{g}$, and $1,000 \mu \mathrm{l}$ of the supernatant of the centrifugation was transfered to a new $1.5 \mathrm{ml}$ centrifuge tube. The tube was centrifuged for $3 \mathrm{~min}$ at $13,000 \mathrm{x}$ g to precipitate bacteria and the supernatant was discarded. Then $1,000 \mu l$ of Reagent II of positive identification kits for blood culture was added in the precipitation, shocked for $5 \mathrm{sec}$, and centrifuged for $3 \mathrm{~min}$ at $13,000 \mathrm{xg}$, and the supernatant was removed and $40 \mu \mathrm{l}$ of Reagent III of positive BC identification kits was added to the precipitation, shocked for $30 \mathrm{sec}$ and placed for $5 \mathrm{~min}$. Finally, the mixture was centrifuged at $13,000 \mathrm{x} \mathrm{g}$ for $1 \mathrm{~min}$ and $2 \mu \mathrm{l}$ of the supernatant was added to the 384 target plates (Clin-ToF-II, Bioyong Technologies Inc.). All the centrifugation steps were carried out at $25^{\circ} \mathrm{C}$.

MALDI-TOF MS analysis. After drying the bacterial pellet on a MALDI-TOF MS target plate at room temperature $1 \mu \mathrm{l}$ reagent $\mathrm{IV}$ and $1 \mu \mathrm{l}$ reagent $\mathrm{V}$ was added onto each spot successively. After the target plate was analyzed by MALDI-TOF MS (Clin-ToF-II; Bioyong Technologies Inc.), the spectra was automatically captured by the BE V3.2 system and and matched with database (Clin-ToF-II; Bioyong Technologies Inc.).

Results of the analysis are presented as a confidence score. According to manufacturer's instructions, a confidence score $<20$ indicated no reliable identification, a confidence score between 20 and 25 was considered identification to the genus level, and a confidence score $\geq 25$ indicated identification to the species level. The identification with a confidence score $\geq 25$ was considered accurate.

Statistical analysis. Pearson's chi-square test and Fisher's exact test were performed to analyse results using the Thermo blood culture bottles and Scanker blood culture bottles. The statistical analyses were conducted using SPSS software (v18.0; SPSS). $\mathrm{P}<0.05$ was considered to indicate a statistically significant difference.

\section{Results}

In total, 400 positive BCs were included in the study (200 Thermo BCs and 200 Scenker BCs). The results of direct MS identification of the positive $\mathrm{BCs}$ were compared with routine biochemical identification (Table I). 
Table I. Identification of Thermo and Scenker positive BCs by MALDI-TOF MS.

\begin{tabular}{|c|c|c|c|c|c|}
\hline Strains & $\begin{array}{c}\text { Routine } \\
\text { biochemical } \\
\text { identification }\end{array}$ & $\begin{array}{c}\text { Accurate } \\
\text { nos. }\end{array}$ & $\begin{array}{c}\text { Consistency of } \\
\text { identification of Thermo } \\
\text { positive BCs with routine } \\
\text { biochemical identification }(\%)\end{array}$ & $\begin{array}{c}\text { Accurate } \\
\text { nos. }\end{array}$ & $\begin{array}{c}\text { Consistency of } \\
\text { identification of } \\
\text { Scenker positive BCs } \\
\text { with routine } \\
\text { biochemical identification }(\%)\end{array}$ \\
\hline Gram-positive bacteria & 91 & 86 & 94.51 & 86 & 94.51 \\
\hline Gram-negative bacteria & 97 & 94 & 96.91 & 95 & 97.94 \\
\hline Candida & 12 & 9 & 75.00 & 8 & 66.67 \\
\hline Total & 200 & 189 & 94.50 & 189 & 94.50 \\
\hline
\end{tabular}

Results were analyzed for significance using the Pearson's chi-square test and Fisher's exact test for comparisons. $\mathrm{P}<0.05$ was considered statistically significant. There is no significant difference of consistency rate of identification between the two kinds of BCs.

As shown in Table I, microorganisms isolated from Thermo and Scenker positive BCs were identified with the accuracy of $94.5 \%$ (189/200) and $94.5 \%$ (189/200), respectively. $96.9 \%$ (94/97) and $97.9 \%(95 / 97)$ of gram-negative bacteria were correctly identified to species level from Thermo and Scenker positive BCs, respectively, 94.5\% (86/91) and 94.5\% (86/91) strains of gram-positive bacteria were correctly identified to species level from Thermo and Scenker positive BCs, respectively. A total of 9 and 8 strains of Candida species were correctly identified to species level from Thermo and Scenker positive BCs, respectively.

In general, the consistency rate of identification from Thermo BCs: $\mathrm{G}^{-}>\mathrm{G}^{+}>$Candida $(96.9>94.5>75.0 \%)$. The consistency rate of identification from Scenker BCs: $\mathrm{G}^{-}>\mathrm{G}^{+}>$Candida $(97.9>94.5>66.7 \%)$. There is no significant difference in consistency rate of identification between the two kinds of BCs.

Identification of Gram-positive bacteria by MALDI-TOF MS. As shown in Table II, 86 gram-positive bacteria isolated from Thermo positive BCs were identified with confidence scores $>25$, while 90 strains were identified with confidence scores $>20$ and 1 strain was identified with confidence score $<20$. A total of 18 strains of Streptococcus were identified with confidence scores $>25$, while 2 strains of Streptococcus anginosus were misidentified as Candida parapsilosis and Propionibacterium acnes, respectively; 43 strains of Staphylococcus were identified with the confidence scores $>25$, while 1 strain of Staphylococcus hominis was misidentified as Propionibacterium acnes. All 14 strains of Enterococcus from Thermo BCs were correctly identified with the confidence scores $>25$.

As shown in Table III, 86 gram-positive bacteria strains isolated from Scenker positive BCs were identified with confidence scores $>25,3$ strains were identified with confidence scores $<20$ and 20 strains of Streptococcus were identified with the confidence scores $>25$, while 1 strain of Streptococcus pneumoniae was misidentified as Streptococcus dysgalactiae. In total, 42 strains of Staphylococcus were identified with the confidence scores $>25$, while 2 strains of Staphylococcus epidermidis were misidentified as Nocardia thailandica. All 14 strains of Enterococcus isolated from Scenker BCs were correctly identified with the confidence score $>25$.

Identification of Gram-negative bacteria by MALDI-TOF MS. As shown in Table IV, 94 gram-negative bacteria isolated from Thermo positive BCs were identified with confidence scores $>25$, while 2 strains were identified with confidence scores $>20$ and 1 strain was identified with a confidence score $<20$. In total, 47 of 48 Enterobacter strains isolated from Thermo positive BCs were correctly identified with the confidence scores $>25$, while 1 strain of Serratia marcescens was misidentified as Atopobium rimae. All of 18 strains of Pseudomonas isolated from Thermo BCs were correctly identified with the confidence scores $>25$.

As shown in Table V, 95 Gram-negative strains isolated from Scenker positive BCs were identified with confidence scores $>25$, while 2 strains were misidentified with confidence scores in the range 20-24. All 18 strains of Pseudomonas isolated from Scenker BCs were correctly identified with the confidence scores $>25$.

Identification of candida by MALDI-TOF MS. As shown in Table VI, of these 12 Candida strains isolated from Thermo BCs, 9 strains were identified with confidence scores $>25$, while 1 strain was identified with a confidence score $<20$. Four strains of Candida albicans complex were identified with the confidence scores $>20$, while 1 strain of $C$. albicans complex was misidentified as Mycobacterium bovis. Two strains of C.glabrata were identified with the confidence scores $>25$, while two strains of $C$. glabrata misidentified as Mycobacterium tuberculosis and Candida parapsilosis, respectively. All 5 strains of Candida tropicalis from Thermo BCs were correctly identified with the confidence scores $>25$.

As shown in Table VII, of these 12 Candida strains isolated from Scenker BCs, 8 strains were identified with confidence scores $>25$, while 2 strains were identified with confidence scores $<20$. Two strains of $C$.albicans complex were identified with the confidence scores $>25$, while 2 strains of $C$.albicans complex were misidentified as Alloiococcus otitis. One strain of Candida glabrata was identified with the confidence score 
Table II. The identity reliability of Gram-positive bacteria cultured by Thermo BC bottles.

\begin{tabular}{|c|c|c|c|c|c|c|c|c|c|}
\hline \multirow[b]{3}{*}{ Pathogens } & \multirow[b]{3}{*}{$\begin{array}{c}\text { Test } \\
\text { strains }\end{array}$} & \multicolumn{6}{|c|}{ Reliability score } & \multirow[b]{3}{*}{$\begin{array}{c}\text { Wrong } \\
\text { number }\end{array}$} & \multirow[b]{3}{*}{$\begin{array}{l}\text { Error } \\
\text { rate }(\%)\end{array}$} \\
\hline & & \multicolumn{2}{|c|}{$20-24$} & \multicolumn{2}{|c|}{$\geq 25.000$} & \multicolumn{2}{|c|}{$<20.000$} & & \\
\hline & & Strains & $\begin{array}{c}\text { Distribution } \\
\text { Ratio (\%) }\end{array}$ & Strains & $\begin{array}{c}\text { Distribution } \\
\text { Ratio (\%) }\end{array}$ & Strains & $\begin{array}{c}\text { Distribution } \\
\text { Ratio (\%) }\end{array}$ & & \\
\hline \multicolumn{10}{|l|}{ Staphylococcus } \\
\hline Staphylococcus epidermidis & 10 & 0 & 0.0 & 10 & 100.0 & 0 & 0.0 & 0 & 0.0 \\
\hline Staphylococcus aureus & 12 & 0 & 0.0 & 12 & 100.0 & 0 & 0.0 & 0 & 0.0 \\
\hline Staphylococcus capitis & 4 & 0 & 0.0 & 4 & 100.0 & 0 & 0.0 & 0 & 0.0 \\
\hline Staphylococcus cohnii & 2 & 0 & 0.0 & 2 & 100.0 & 0 & 0.0 & 0 & 0.0 \\
\hline Staphylococcus haemolyticus & 5 & 0 & 0.0 & 5 & 100.0 & 0 & 0.0 & 0 & 0.0 \\
\hline Staphylococcus hominis & 6 & 1 & 16.7 & 5 & 83.3 & 0 & 0.0 & 1 & 16.7 \\
\hline Staphylococcus lugdunensis & 1 & 0 & 0.0 & 1 & 100.0 & 0 & 0.0 & 0 & 0.0 \\
\hline Staphylococcus saprophyticus & 1 & 0 & 0.0 & 1 & 100.0 & 0 & 0.0 & 0 & 0.0 \\
\hline Staphylococcus sciuri & 1 & 0 & 0.0 & 1 & 100.0 & 0 & 0.0 & 0 & 0.0 \\
\hline Staphylococcus simulans & 1 & 0 & 0.0 & 1 & 100.0 & 0 & 0.0 & 0 & 0.0 \\
\hline Staphylococcus warneri & 1 & 0 & 0.0 & 1 & 100.0 & 0 & 0.0 & 0 & 0.0 \\
\hline \multicolumn{10}{|l|}{ Streptococcus } \\
\hline Streptococcus agalactiae & 6 & 0 & 0.0 & 6 & 100.0 & 0 & 0.0 & 0 & 0.0 \\
\hline Streptococcus anginosus group & 7 & 2 & 28.6 & 5 & 71.4 & 0 & 0.0 & 2 & 28.6 \\
\hline Streptococcus dysgalactiae & 1 & 0 & 0.0 & 1 & 100.0 & 0 & 0.0 & 0 & 0.0 \\
\hline Streptococcus gallolyticus & 1 & 0 & 0.0 & 1 & 100.0 & 0 & 0.0 & 0 & 0.0 \\
\hline Streptococcus mitis group & 2 & 0 & 0.0 & 2 & 100.0 & 0 & 0.0 & 0 & 0.0 \\
\hline Streptococcus pneumoniae & 3 & 0 & 0.0 & 3 & 100.0 & 0 & 0.0 & 0 & 0.0 \\
\hline \multicolumn{10}{|l|}{ Enterococcus } \\
\hline Enterococcus avium & 2 & 0 & 0.0 & 2 & 100.0 & 0 & 0.0 & 0 & 0.0 \\
\hline Enterococcus faecalis & 6 & 0 & 0.0 & 6 & 100.0 & 0 & 0.0 & 0 & 0.0 \\
\hline Enterococcus faecium & 6 & 0 & 0.0 & 6 & 100.0 & 0 & 0.0 & 0 & 0.0 \\
\hline \multicolumn{10}{|l|}{ Others } \\
\hline Bacillus cereus & 2 & 0 & 0.0 & 2 & 100.0 & 0 & 0.0 & 0 & 0.0 \\
\hline Clostridium tertium & 1 & 0 & 0.0 & 1 & 100.0 & 0 & 0.0 & 0 & 0.0 \\
\hline Corynebacterium amycolatum & 1 & 0 & 0.0 & 1 & 100.0 & 0 & 0.0 & 0 & 0.0 \\
\hline Corynebacterium jeikeium & 1 & 1 & 100.0 & 0 & 0.0 & 0 & 0.0 & 1 & 100.0 \\
\hline Corynebacterium striatum & 1 & 0 & 0.0 & 1 & 100.0 & 0 & 0.0 & 0 & 0.0 \\
\hline Lactobacillus paracasei & 1 & 0 & 0.0 & 1 & 100.0 & 0 & 0.0 & 0 & 0.0 \\
\hline Lactococcus garvieae & 1 & 0 & 0.0 & 1 & 100.0 & 0 & 0.0 & 0 & 0.0 \\
\hline Micrococcus luteus & 2 & 0 & 0.0 & 1 & 50.0 & 1 & 50.0 & 1 & 50.0 \\
\hline Paenibacillus alvei & 1 & 0 & 0.0 & 1 & 100.0 & 0 & 0.0 & 0 & 0.0 \\
\hline Rothia mucilaginosa & 2 & 0 & 0.0 & 2 & 100.0 & 0 & 0.0 & 0 & 0.0 \\
\hline All & 91 & 4 & 98.9 & 86 & 94.5 & 1 & 1.1 & 5 & 5.5 \\
\hline
\end{tabular}

$>25$, while 2 strains of Candida glabrata were misidentified as Streptococcusdysgalactiae. All 5 strains of C.tropicalis isolated from Scenker BCs were correctly identified with the confidence scores $>25$.

\section{Discussion}

Blood stream infection is one of the severe infectious diseases (7), which causes systemic infections, and even multiple organ failure. The distribution of pathogens causing blood stream infection is changing constantly and the resistance is increasing (8). At present, the 'gold standard' for clinical diagnosis of bloodstream infection is still the traditional blood culture and identification, which needs at least $48 \mathrm{~h}(9,10)$. The mortality rate of septicaemia patients is as high as 25 to $50 \%$, and the delay of antiobiotic treatment per hour will lead to a $7.6 \%$ reduction in survival rate within the first $6 \mathrm{~h}$. Therefore, timely and accurate identification of pathogens of blood 
Table III. The identity reliability of Gram-positive bacteria cultured by Scenker BC bottles.

\begin{tabular}{|c|c|c|c|c|c|c|c|c|c|}
\hline \multirow[b]{3}{*}{ Pathogens } & \multirow[b]{3}{*}{$\begin{array}{c}\text { Test } \\
\text { strains }\end{array}$} & \multicolumn{6}{|c|}{ Reliability score } & \multirow[b]{3}{*}{$\begin{array}{l}\text { Wrong } \\
\text { number }\end{array}$} & \multirow[b]{3}{*}{$\begin{array}{c}\text { Error } \\
\text { rate }(\%)\end{array}$} \\
\hline & & \multicolumn{2}{|c|}{$20-24$} & \multicolumn{2}{|c|}{$\geq 25.000$} & \multicolumn{2}{|c|}{$<20.000$} & & \\
\hline & & Strains & $\begin{array}{c}\text { Distribution } \\
\text { Ratio (\%) }\end{array}$ & Strains & $\begin{array}{c}\text { Distribution } \\
\text { Ratio (\%) }\end{array}$ & Strains & $\begin{array}{c}\text { Distribution } \\
\text { Ratio (\%) }\end{array}$ & & \\
\hline \multicolumn{10}{|l|}{ Staphylococcus } \\
\hline Staphylococcus epidermidis & 10 & 0 & 0.0 & 8 & 80.0 & 2 & 20.0 & 2 & 20.0 \\
\hline Staphylococcus aureus & 12 & 0 & 0.0 & 12 & 100.0 & 0 & 0.0 & 0 & 0.0 \\
\hline Staphylococcus capitis & 4 & 0 & 0.0 & 4 & 100.0 & 0 & 0.0 & 0 & 0.0 \\
\hline Staphylococcus cohnii & 2 & 0 & 0.0 & 2 & 100.0 & 0 & 0.0 & 0 & 0.0 \\
\hline Staphylococcus haemolyticus & 5 & 0 & 0.0 & 5 & 100.0 & 0 & 0.0 & 0 & 0.0 \\
\hline Staphylococcus hominis & 6 & 0 & 0.0 & 6 & 100.0 & 0 & 0.0 & 0 & 0.0 \\
\hline Staphylococcus lugdunensis & 1 & 0 & 0.0 & 1 & 100.0 & 0 & 0.0 & 0 & 0.0 \\
\hline Staphylococcus saprophyticus & 1 & 0 & 0.0 & 1 & 100.0 & 0 & 0.0 & 0 & 0.0 \\
\hline Staphylococcus sciuri & 1 & 0 & 0.0 & 1 & 100.0 & 0 & 0.0 & 0 & 0.0 \\
\hline Staphylococcus simulans & 1 & 0 & 0.0 & 1 & 100.0 & 0 & 0.0 & 0 & 0.0 \\
\hline Staphylococcus warneri & 1 & 0 & 0.0 & 1 & 100.0 & 0 & 0.0 & 0 & 0.0 \\
\hline \multicolumn{10}{|l|}{ Streptococcus } \\
\hline Streptococcus agalactiae & 6 & 0 & 0.0 & 6 & 100.0 & 0 & 0.0 & 0 & 0.0 \\
\hline Streptococcus anginosus group & 7 & 0 & 0.0 & 7 & 100.0 & 0 & 0.0 & 0 & 0.0 \\
\hline Streptococcus dysgalactiae & 1 & 0 & 0.0 & 1 & 100.0 & 0 & 0.0 & 0 & 0.0 \\
\hline Streptococcus gallolyticus & 1 & 0 & 0.0 & 1 & 100.0 & 0 & 0.0 & 0 & 0.0 \\
\hline Streptococcus mitis group & 2 & 0 & 0.0 & 2 & 100.0 & 0 & 0.0 & 0 & 0.0 \\
\hline Streptococcus pneumoniae & 3 & 0 & 0.0 & 3 & 100.0 & 0 & 0.0 & 1 & 33.3 \\
\hline \multicolumn{10}{|l|}{ Enterococcus } \\
\hline Enterococcus avium & 2 & 0 & 0.0 & 2 & 100.0 & 0 & 0.0 & 0 & 0.0 \\
\hline Enterococcus faecalis & 6 & 0 & 0.0 & 6 & 100.0 & 0 & 0.0 & 0 & 0.0 \\
\hline Enterococcus faecium & 6 & 0 & 0.0 & 6 & 100.0 & 0 & 0.0 & 0 & 0.0 \\
\hline \multicolumn{10}{|l|}{ Others } \\
\hline Bacillus cereus & 2 & 0 & 0.0 & 2 & 100.0 & 0 & 0.0 & 0 & 0.0 \\
\hline Clostridium tertium & 1 & 0 & 0.0 & 1 & 100.0 & 0 & 0.0 & 0 & 0.0 \\
\hline Corynebacterium amycolatum & 1 & 0 & 0.0 & 1 & 100.0 & 0 & 0.0 & 0 & 0.0 \\
\hline Corynebacterium jeikeium & 1 & 0 & 0.0 & 1 & 100.0 & 0 & 0.0 & 0 & 0.0 \\
\hline Corynebacterium striatum & 1 & 0 & 0.0 & 1 & 100.0 & 0 & 0.0 & 0 & 0.0 \\
\hline Lactobacillus paracasei & 1 & 0 & 0.0 & 1 & 100.0 & 0 & 0.0 & 0 & 0.0 \\
\hline Lactococcus garvieae & 1 & 0 & 0.0 & 1 & 100.0 & 0 & 0.0 & 0 & 0.0 \\
\hline Micrococcus luteus & 2 & 1 & 50.0 & 0 & 0.0 & 1 & 50.0 & 2 & 100.0 \\
\hline Paenibacillus alvei & 1 & 0 & 0.0 & 1 & 100.0 & 0 & 0.0 & 0 & 0.0 \\
\hline Rothia mucilaginosa & 2 & 0 & 0.0 & 2 & 100.0 & 0 & 0.0 & 0 & 0.0 \\
\hline All & 91 & 2 & 2.2 & 86 & 94.5 & 3 & 3.3 & 5 & 5.5 \\
\hline
\end{tabular}

stream infection and shortening the reporting time is essential for optimizing the treatment of antibiotics and improving the prognosis of patients $(11,12)$. Getting accurate etiological diagnosis and drug sensitivity test as soon as possible is crucial to the diagnosis and treatment of BSIs. With the application of MALDI-TOF MS in clinical diagnosis, researchers began to make efforts to directly identify blood culture samples by MALDI-TOF MS. La Scola and Raoult (2009), first proposed the direct detection of blood culture positive specimens with three fluoroacetic acid or formic acid to lysine protein. After preparation with three fluoroacetic acids, 370 (66\%) of 562 cases of positive blood culture could be correctly identified (13). Subsequently, a large number of studies have proved that the blood culture samples were processed by the bacterial enrichment technology and identified directly by MALDI-TOF MS. Compared with traditional method, direct 
Table IV. The identity reliability of Gram-negative bacteria cultured by Thermo BC bottles.

\begin{tabular}{|c|c|c|c|c|c|c|c|c|c|}
\hline \multirow[b]{3}{*}{ Pathogens } & \multirow[b]{3}{*}{$\begin{array}{c}\text { Test } \\
\text { strains }\end{array}$} & \multicolumn{6}{|c|}{ Reliability score } & \multirow[b]{3}{*}{$\begin{array}{l}\text { Wrong } \\
\text { number }\end{array}$} & \multirow[b]{3}{*}{$\begin{array}{l}\text { Error } \\
\text { rate }(\%)\end{array}$} \\
\hline & & \multicolumn{2}{|c|}{$20-24$} & \multicolumn{2}{|c|}{$\geq 25.000$} & \multicolumn{2}{|c|}{$<20.000$} & & \\
\hline & & Strains & $\begin{array}{l}\text { Distribution } \\
\text { Ratio }(\%)\end{array}$ & Strains & $\begin{array}{l}\text { Distribution } \\
\text { Ratio (\%) }\end{array}$ & Strains & $\begin{array}{l}\text { Distribution } \\
\text { Ratio (\%) }\end{array}$ & & \\
\hline \multicolumn{10}{|l|}{ Enterobacter } \\
\hline Enterobacter aerogenes & 3 & 0 & 0.0 & 3 & 100.0 & 0 & 100.0 & 0 & 0.0 \\
\hline Escherichia coli & 10 & 0 & 0.0 & 10 & 100.0 & 0 & 100.0 & 0 & 0.0 \\
\hline Klebsiella pneumoniae & 7 & 0 & 0.0 & 7 & 100.0 & 0 & 100.0 & 0 & 0.0 \\
\hline Serratia marcescens & 4 & 0 & 0.0 & 3 & 75.0 & 1 & 25.0 & 1 & 25.0 \\
\hline Enterobacter cloacae complex & 5 & 0 & 0.0 & 5 & 100.0 & 0 & 100.0 & 0 & 0.0 \\
\hline Salmonella sp. & 5 & 0 & 0.0 & 5 & 100.0 & 0 & 100.0 & 0 & 0.0 \\
\hline Proteus mirabilis & 6 & 0 & 0.0 & 6 & 100.0 & 0 & 100.0 & 0 & 0.0 \\
\hline Citrobacter braakii & 1 & 0 & 0.0 & 1 & 100.0 & 0 & 100.0 & 0 & 0.0 \\
\hline Citrobacter freundii & 1 & 0 & 0.0 & 1 & 100.0 & 0 & 100.0 & 0 & 0.0 \\
\hline Klebsiella oxytoca & 3 & 0 & 0.0 & 3 & 100.0 & 0 & 100.0 & 0 & 0.0 \\
\hline Morganella morganii & 2 & 0 & 0.0 & 2 & 100.0 & 0 & 100.0 & 0 & 0.0 \\
\hline Pantoea agglomerans & 1 & 0 & 0.0 & 1 & 100.0 & 0 & 100.0 & 0 & 0.0 \\
\hline \multicolumn{10}{|l|}{ Monomonas } \\
\hline Pseudomonas aeruginosa & 12 & 0 & 0.0 & 12 & 100.0 & 0 & 100.0 & 0 & 0.0 \\
\hline Pseudomonas monteilii & 1 & 0 & 0.0 & 1 & 100.0 & 0 & 100.0 & 0 & 0.0 \\
\hline Pseudomonas putida & 1 & 0 & 0.0 & 1 & 100.0 & 0 & 100.0 & 0 & 0.0 \\
\hline Stenotrophomonas maltophilia & 4 & 0 & 0.0 & 4 & 100.0 & 0 & 100.0 & 0 & 0.0 \\
\hline \multicolumn{10}{|l|}{ Others } \\
\hline Achromobacter piechaudii & 1 & 1 & 0.0 & 0 & 0.0 & 0 & 100.0 & 1 & 100.0 \\
\hline $\begin{array}{l}\text { Achromobacter xylosoxidans } \\
\text { complex }\end{array}$ & 2 & 0 & 0.0 & 2 & 100.0 & 0 & 100.0 & 0 & 0.0 \\
\hline $\begin{array}{l}\text { Aeromonas caviae/hydrophilal } \\
\text { jandaei complex }\end{array}$ & 3 & 0 & 0.0 & 3 & 100.0 & 0 & 100.0 & 0 & 0.0 \\
\hline Burkholderia cepacia complex & 4 & 0 & 0.0 & 4 & 100.0 & 0 & 100.0 & 0 & 0.0 \\
\hline $\begin{array}{l}\text { Chryseobacterium gleum/ } \\
\text { indologenes complex }\end{array}$ & 1 & 0 & 0.0 & 1 & 100.0 & 0 & 100.0 & 0 & 0.0 \\
\hline Haemophilus influenzae & 5 & 0 & 0.0 & 5 & 100.0 & 0 & 100.0 & 0 & 0.0 \\
\hline Moraxella catarrhalis & 2 & 0 & 0.0 & 2 & 100.0 & 0 & 100.0 & 0 & 0.0 \\
\hline Myroides odoratus & 1 & 0 & 0.0 & 1 & 100.0 & 0 & 100.0 & 0 & 0.0 \\
\hline Ochrobactrum anthropi & 1 & 0 & 0.0 & 1 & 100.0 & 0 & 100.0 & 0 & 0.0 \\
\hline Pandoraea pnomenusa & 1 & 0 & 0.0 & 1 & 100.0 & 0 & 100.0 & 0 & 0.0 \\
\hline Providencia stuartii & 1 & 0 & 0.0 & 1 & 100.0 & 0 & 100.0 & 0 & 0.0 \\
\hline Ralstonia mannitolilytica & 1 & 0 & 0.0 & 0 & 0.0 & $1^{*}$ & 100.0 & 1 & 100.0 \\
\hline Vibrio cholerae & 1 & 0 & 0.0 & 1 & 100.0 & 0 & 0.0 & 0 & 0.0 \\
\hline $\begin{array}{l}\text { Acinetobacter calcoaceticus- } \\
\text { baumannii complex }\end{array}$ & 7 & 0 & 0.0 & 7 & 100.0 & 0 & 0.0 & 0 & 0.0 \\
\hline All & 97 & 1 & 1.0 & 94 & 96.9 & 2 & 2.1 & 3 & 3.1 \\
\hline
\end{tabular}

pathogen identification of BCs by MALDI-TOF MS meets better the needs of rapid clinical diagnosis. However, these studies showed that the identification accuracy was less than $85.0 \%$ (14-19).

There are several in-house methods developed, but none is widely used because there is no standardization and the performance depends greatly on operators' skills. Moreover, different sample processing methods have great impact on the diagnosis results $(14,20)$. There are several imported commercial kits for sample preparation in China, but the prices are relative high and it may be an additional burden for the clinical laboratories. The Bioyong sample preparation kit 
Table V. The identity reliability of Gram-negative bacteria cultured by Scenker BC bottles.

\begin{tabular}{|c|c|c|c|c|c|c|c|c|c|}
\hline \multirow[b]{3}{*}{ Pathogens } & \multirow[b]{3}{*}{$\begin{array}{c}\text { Test } \\
\text { strains }\end{array}$} & \multicolumn{6}{|c|}{ Reliability score } & \multirow[b]{3}{*}{$\begin{array}{l}\text { Wrong } \\
\text { number }\end{array}$} & \multirow[b]{3}{*}{$\begin{array}{c}\text { Error } \\
\text { rate }(\%)\end{array}$} \\
\hline & & \multicolumn{2}{|c|}{$20-24$} & \multicolumn{2}{|c|}{$\geq 25.000$} & \multicolumn{2}{|c|}{$<20.000$} & & \\
\hline & & Strains & $\begin{array}{l}\text { Distribution } \\
\text { Ratio }(\%)\end{array}$ & Strains & $\begin{array}{l}\text { Distribution } \\
\text { Ratio (\%) }\end{array}$ & Strains & $\begin{array}{l}\text { Distribution } \\
\text { Ratio }(\%)\end{array}$ & & \\
\hline \multicolumn{10}{|l|}{ Enterobacter } \\
\hline Enterobacter aerogenes & 3 & 0 & 0.0 & 3 & 100.0 & 0 & 0.0 & 0 & 0.0 \\
\hline Escherichia coli & 10 & 0 & 0.0 & 10 & 100.0 & 0 & 0.0 & 0 & 0.0 \\
\hline Klebsiella pneumoniae & 7 & 0 & 0.0 & 7 & 100.0 & 0 & 0.0 & 0 & 0.0 \\
\hline Serratia marcescens & 4 & 0 & 0.0 & 4 & 100.0 & 0 & 0.0 & 0 & 0.0 \\
\hline Enterobacter cloacae complex & 5 & 0 & 0.0 & 5 & 100.0 & 0 & 0.0 & 0 & 0.0 \\
\hline Salmonella sp & 5 & 0 & 0.0 & 5 & 100.0 & 0 & 0.0 & 0 & 0.0 \\
\hline Proteus mirabilis & 6 & 0 & 0.0 & 6 & 100.0 & 0 & 0.0 & 0 & 0.0 \\
\hline Citrobacter braakii & 1 & 0 & 0.0 & 1 & 100.0 & 0 & 0.0 & 0 & 0.0 \\
\hline Citrobacter freundii & 1 & 0 & 0.0 & 1 & 100.0 & 0 & 0.0 & 0 & 0.0 \\
\hline Klebsiella oxytoca & 3 & 0 & 0.0 & 3 & 100.0 & 0 & 0.0 & 0 & 0.0 \\
\hline Morganella morganii & 2 & 0 & 0.0 & 2 & 100.0 & 0 & 0.0 & 0 & 0.0 \\
\hline Pantoea agglomerans & 1 & 0 & 0.0 & 1 & 100.0 & 0 & 0.0 & 0 & 0.0 \\
\hline \multicolumn{10}{|l|}{ Monomonas } \\
\hline Pseudomonas aeruginosa & 12 & 0 & 0.0 & 12 & 100.0 & 0 & 0.0 & 0 & 0.0 \\
\hline Pseudomonas monteilii & 1 & 0 & 0.0 & 1 & 100.0 & 0 & 0.0 & 0 & 0.0 \\
\hline Pseudomonas putida & 1 & 0 & 0.0 & 1 & 100.0 & 0 & 0.0 & 0 & 0.0 \\
\hline Stenotrophomonas maltophilia & 4 & 0 & 0.0 & 4 & 100.0 & 0 & 0.0 & 0 & 0.0 \\
\hline \multicolumn{10}{|l|}{ Others } \\
\hline Achromobacter piechaudii & 1 & 0 & 0.0 & 1 & 100.0 & 0 & 0.0 & 0 & 0.0 \\
\hline $\begin{array}{l}\text { Achromobacter xylosoxidans } \\
\text { complex }\end{array}$ & 2 & 0 & 0.0 & 2 & 100.0 & 0 & 0.0 & 0 & 0.0 \\
\hline $\begin{array}{l}\text { Aeromonas caviae/hydrophila/ } \\
\text { jandaei complex }\end{array}$ & 3 & 0 & 0.0 & 3 & 100.0 & 0 & 0.0 & 0 & 0.0 \\
\hline Burkholderia cepacia complex & 4 & 0 & 0.0 & 4 & 100.0 & 0 & 0.0 & 0 & 0.0 \\
\hline $\begin{array}{l}\text { Chryseobacterium gleum/ } \\
\text { indologenes complex }\end{array}$ & 1 & 1 & 100.0 & 0 & 0.0 & 0 & 0.0 & 1 & 100.0 \\
\hline Haemophilus influenzae & 5 & 0 & 0.0 & 5 & 100.0 & 0 & 0.0 & 0 & 0.0 \\
\hline Moraxella catarrhalis & 2 & 0 & 0.0 & 2 & 100.0 & 0 & 0.0 & 0 & 0.0 \\
\hline Myroides odoratus & 1 & 1 & 100.0 & 0 & 0.0 & 0 & 0.0 & 1 & 100.0 \\
\hline Ochrobactrum anthropi & 1 & 0 & 0.0 & 1 & 100.0 & 0 & 0.0 & 0 & 0.0 \\
\hline Pandoraea pnomenusa & 1 & 0 & 0.0 & 1 & 100.0 & 0 & 0.0 & 0 & 0.0 \\
\hline Providencia stuartii & 1 & 0 & 0.0 & 1 & 100.0 & 0 & 0.0 & 0 & 0.0 \\
\hline Ralstonia mannitolilytica & 1 & 0 & 0.0 & 1 & 100.0 & 0 & 0.0 & 0 & 0.0 \\
\hline Vibrio cholerae & 1 & 0 & 0.0 & 1 & 100.0 & 0 & 0.0 & 0 & 0.0 \\
\hline $\begin{array}{l}\text { Acinetobacter calcoaceticus- } \\
\text { baumannii complex }\end{array}$ & 7 & 0 & 0.0 & 7 & 100.0 & 0 & 0.0 & 0 & 0.0 \\
\hline All & 97 & 2 & 2.1 & 95 & 97.9 & 0 & 0.0 & 2 & 2.1 \\
\hline
\end{tabular}

was produced in China locally, aimed to reduce costs and to increase sensitivity. This study using Bioyong kit shows that the accurate identification result could be obtained within $1 \mathrm{~h}$, while the traditional identification needs more $24-48 \mathrm{~h}$, which is crucial for BSIs, especially for severely ill patients in need of quick treatment $(18,21)$. Compared with previous studies, our results show that the identification accuracy of this method among Gram-negative and Gram-positive bacteria is above $94.0 \%$.

Referring to the identification standard recommended by the instrument, the result shows that, the MALDI-TOF MS method is more accurate for Gram-negative bacteria 
Table VI. The identity reliability of Candida cultured by Thermo BC bottles.

\begin{tabular}{|c|c|c|c|c|c|c|c|c|c|}
\hline \multirow[b]{3}{*}{ Pathogens } & \multirow[b]{3}{*}{$\begin{array}{c}\text { Test } \\
\text { strains }\end{array}$} & \multicolumn{6}{|c|}{ Reliability score } & \multirow[b]{3}{*}{$\begin{array}{l}\text { Wrong } \\
\text { number }\end{array}$} & \multirow[b]{3}{*}{$\begin{array}{l}\text { Error } \\
\text { rate }(\%)\end{array}$} \\
\hline & & \multicolumn{2}{|c|}{$20-24$} & \multicolumn{2}{|c|}{$\geq 25.000$} & \multicolumn{2}{|c|}{$<20.000$} & & \\
\hline & & Strains & $\begin{array}{c}\text { Distribution } \\
\text { Ratio (\%) }\end{array}$ & Strains & $\begin{array}{c}\text { Distribution } \\
\text { Ratio (\%) }\end{array}$ & Strains & $\begin{array}{c}\text { Distribution } \\
\text { Ratio (\%) }\end{array}$ & & \\
\hline \multicolumn{10}{|l|}{ Candida } \\
\hline Candida albicans complex & 4 & 1 & 25.0 & 3 & 75.0 & 0 & 0.0 & 1 & 25.0 \\
\hline Candida glabrata & 3 & 0 & 0.0 & 2 & 66.7 & 1 & 33.3 & 2 & 66.7 \\
\hline Candida tropicalis & 5 & 0 & 0.0 & 5 & 100.0 & 0 & 0.0 & 0 & 0.0 \\
\hline All & 12 & 1 & 8.3 & 10 & 83.3 & 1 & 8.3 & 3 & 25.0 \\
\hline
\end{tabular}

Table VII. The identity reliability of Candida cultured by Scenker BCs.

\begin{tabular}{|c|c|c|c|c|c|c|c|c|c|}
\hline \multirow[b]{3}{*}{ Pathogens } & \multirow[b]{3}{*}{$\begin{array}{c}\text { Test } \\
\text { strains }\end{array}$} & \multicolumn{6}{|c|}{ Reliability score } & \multirow[b]{3}{*}{$\begin{array}{l}\text { Wrong } \\
\text { number }\end{array}$} & \multirow[b]{3}{*}{$\begin{array}{l}\text { Error } \\
\text { rate }(\%)\end{array}$} \\
\hline & & \multicolumn{2}{|r|}{$20-24$} & \multicolumn{2}{|c|}{$\geq 25.000$} & \multicolumn{2}{|c|}{$<20.000$} & & \\
\hline & & Strains & $\begin{array}{c}\text { Distribution } \\
\text { Ratio (\%) }\end{array}$ & Strains & $\begin{array}{c}\text { Distribution } \\
\text { Ratio (\%) }\end{array}$ & Strains & $\begin{array}{c}\text { Distribution } \\
\text { Ratio (\%) }\end{array}$ & & \\
\hline \multicolumn{10}{|l|}{ Candida } \\
\hline Candida albicans complex & 4 & 1 & 25.0 & 2 & 50.0 & 1 & 25.0 & 2 & 50.0 \\
\hline Candida glabrata & 3 & 1 & 33.3 & 1 & 33.3 & 1 & 33.3 & 2 & 66.7 \\
\hline Candida tropicalis & 5 & 0 & 0.0 & 5 & 100.0 & 0 & 0.0 & 0 & 0.0 \\
\hline All & 12 & 2 & 16.7 & 8 & 66.7 & 2 & 16.7 & 4 & 33.3 \\
\hline
\end{tabular}

identification than that of Gram-positive bacteria. Misidentification of Streptococcus and Staphylococcus is mainly related to the following factors: i) there is a high similarity among different Streptococcus groups, such as Streptococcus pneumonia, Streptococcus lactis, Streptococcus suis, Streptococcus oral, Streptococcus dysgalactiae and so on; ii) Gram-positive bacteria cell wall is relative thick which could increase its resistance to dissolution and iii) blood cell component might be an interference factor.

It should be noted that there were some limitations in this study. This study was performed by mock positive blood cultures. The evalution of the pre-treatment kit should be conducted on the clinical positive BCs further on. Furthermore, only monomicrobial growth in BCs was included in this study. The evalution of this method's performance in polymicrobial growth in BCs still need to be investigated. Only 12 yeast strains were adopted. Additional research with larger number of yeasts is needed.

In conclusion, the Bioyong kit could be used to identify rapidly and accurately common organisms in positive BCs to meet the clinical need for rapid diagnosis of pathogens.

\section{Acknowledgements}

The authors would like to thank Bioyong Technologies, Inc., for their technical support.

\section{Funding}

The study was supported by grants from the National Natural Science Foundation of China (81902119) and Jinan Science and Technology Development Plan (201805021).

\section{Availability of data and materials}

The datasets used and/or analyzed during the present study are available from the corresponding author on reasonable request.

\section{Authors' contributions}

YW, ZL and YH contributed to the conception and design of the study. ZS carried out the bacteria identification. YB and YJ performed data analysis. YH wrote the manuscript. WC and MZ performed mock-inoculated blood culture. ZL and $\mathrm{YH}$ are responsible for submitting a competing interests statement on behalf of all authors of the study. All authors read and approved the final version of the manuscript.

\section{Ethics approval and consent to participate}

This study was approved by the Ethics Committee of Shandong Provincial Hospital Affiliated to Shandong First 
Medical University (Jinan, China). Signed informed consent was obtained from the volunteers that participated in the study.

\section{Patient consent for publication}

Not applicable.

\section{Competing interests}

The authors declare that they have no competing interests.

\section{References}

1. Hotchkiss RS, Moldawer LL, Opal SM, Reinhart K, Turnbull IR and Vincent JL: Sepsis and septic shock. Nat Rev Dis Primers 2: 16045,2016

2. Moreira J: Severe sepsis and septic shock. N Engl J Med 369: 2063, 2013

3. Buehler SS, Madison B, Snyder SR, Derzon JH, Cornish NE, Saubolle MA, Weissfeld AS, Weinstein MP, Liebow EB and Wolk DM: Effectiveness of practices to increase timeliness of providing targeted therapy for inpatients with bloodstream infections: A laboratory medicine best practices systematic review and meta-analysis. Clin Microbiol Rev 29: 59-103, 2016.

4. Riedel S and Carroll KC: Early identification and treatment of pathogens in sepsis: Molecular diagnostics and antibiotic choice. Clin Chest Med 37: 191-207, 2016.

5. La Scola B: Intact cell MALDI-TOF mass spectrometry-based approaches for the diagnosis of bloodstream infections. Expert Rev Mol Diagn 11: 287-298, 2011.

6. Dixon P, Davies P, Hollingworth W, Stoddart M and MacGowan A: A systematic review of matrix-assisted laser Desorption/Ionisation time-of-flight mass spectrometry compared to routine microbiological methods for the time taken to identify microbial organisms from positive blood cultures. Eur J Clin Microbiol Infect Dis 34: 863-876, 2015.

7. Cherkaoui A, Hibbs J, Emonet S, Tangomo M, Girard M, Francois P and Schrenzel J: Comparison of two matrix-assisted laser desorption ionization-time of flight mass spectrometry methods with conventional phenotypic identification for routine identification of bacteria to the species level. J Clin Microbiol 48 $1169-1175,2010$.

8. Wiener RS, Ouellette DR, Diamond E, Fan VS, Maurer JR, Mularski RA, Peters JI and Halpern SD: An official American Thoracic Society/American College of Chest Physicians policy statement: The Choosing Wisely top five list in adult pulmonary medicine. Chest 145: 1383-1391, 2014.

9. Martiny D, Dediste A and Vandenberg O: Comparison of an in-house method and the commercial Sepsityper kit for bacterial identification directly from positive blood culture broths by matrix-assisted laser Desorption-Ionisation time-of-flight mass spectrometry. Eur J Clin Microbiol Infect Dis 31: 2269-2281, 2012.
10. Caspar Y, Garnaud C, Raykova M, Bailly S, Bidart M and Maubon D: Superiority of SDS lysis over saponin lysis for direct bacterial identification from positive blood culture bottle by MALDI-TOF MS. Proteomics Clin Appl 11: 5-6, 2017.

11. Lange C, Schubert S, Jung J, Kostrzewa $M$ and Sparbier K: Quantitative matrix-assisted laser desorption ionization-time of flight mass spectrometry for rapid resistance detection. J Clin Microbiol 52: 4155-4162, 2014.

12. Jung JS, Hamacher C, Gross B, Sparbier K, Lange C, Kostrzewa M and Schubert S: Evaluation of a semiquantitative matrix-assisted laser desorption ionization-time of flight mass spectrometry method for rapid antimicrobial susceptibility testing of positive blood cultures. J Clin Microbiol 54: 2820-2824, 2016.

13. La Scola B and Raoult D: Direct identification of bacteria in positive blood culture bottles by matrix-assisted laser desorption ionisation time-of-flight mass spectrometry. PLoS One 4: e8041, 2009.

14. Choi J, Jeong HY, Lee GY, Han S, Han S, Jin B, Lim T, Kim S, Kim DY, Kim HC, et al: Direct, rapid antimicrobial susceptibility test from positive blood cultures based on microscopic imaging analysis. Sci Rep 7: 1148, 2017.

15. Fothergill A, Kasinathan V, Hyman J, Walsh J, Drake T and Wang YF: Rapid identification of bacteria and yeasts from positive-blood-culture bottles by using a lysis-filtration method and matrix-assisted laser desorption ionization-time of flight mass spectrum analysis with the SARAMIS database. J Clin Microbiol 51: 805-809, 2013.

16. Ghosh AK, Paul S, Sood P, Rudramurthy SM, Rajbanshi A, Jillwin TJ and Chakrabarti A: Matrix-assisted laser desorption ionization time-of-flight mass spectrometry for the rapid identification of yeasts causing bloodstream infections. Clin Microbiol Infect 21: 372-378, 2015 .

17. Yonetani S, Ohnishi H, Ohkusu K, Matsumoto T and Watanabe T: Direct identification of microorganisms from positive blood cultures by MALDI-TOF MS using an in-house saponin method. Int J Infect Dis 52: 37-42, 2016.

18. Tanner H, Evans JT, Gossain S and Hussain A: Evaluation of three sample preparation methods for the direct identification of bacteria in positive blood cultures by MALDI-TOF. BMC Res Notes 10: 48, 2017

19. Lin JF, Ge MC, Liu TP, Chang SC and Lu JJ: A simple method for rapid microbial identification from positive monomicrobial blood culture bottles through matrix-assisted laser desorption ionization time-of-flight mass spectrometry. J Microbiol Immunol Infect 51: 659-665, 2018.

20. Kumar A, Roberts D, Wood KE, Light B, Parrillo JE, Sharma S, Suppes R, Feinstein D, Zanotti S, Taiberg L, et al: Duration of hypotension before initiation of effective antimicrobial therapy is the critical determinant of survival in human septic shock. Crit Care Med 34: 1589-1596, 2006.

21. Laupland KB: Incidence of bloodstream infection: A review of population-based studies. Clin Microbiol Infect 19: 492-500, 2013. 